\title{
Study of A1298C MTHFR Gene Polymorphism as a Risk Factor for Neural Tube Defects in the Eastern Algerian Population
}

\author{
Amel Abbas ${ }^{1,2 *}$, Karima Sifi ${ }^{2,3}$, Karima Benembarek ${ }^{3}$, Nourredine Abadi ${ }^{2,3}$ \\ ${ }^{1}$ Medicine faculty, Ouargla University, Ouargla, Algeria \\ ${ }^{2}$ Laboratory of Biology and Molecular Genetics, CHU Benbadis, Constantine, Algeria \\ ${ }^{3}$ Laboratory of Biochemistry, CHU Benbadis, Constantine, Algeria \\ Email: ^mlabbasml@gmail.com
}

How to cite this paper: Abbas, A., Sifi, K., Benembarek, K. and Abadi, N. (2021) Study of A1298C MTHFR Gene Polymorphism as a Risk Factor for Neural Tube Defects in the Eastern Algerian Population. Open Journal of Genetics, 11, 32-41.

https://doi.org/10.4236/ojgen.2021.113004

Received: July 30, 2021

Accepted: September 7, 2021

Published: September 10, 2021

Copyright $\odot 2021$ by author(s) and Scientific Research Publishing Inc. This work is licensed under the Creative Commons Attribution International License (CC BY 4.0).

http://creativecommons.org/licenses/by/4.0/

\begin{abstract}
Background: As C677T mutation, A1298C mutation in methylene tetrahydrofolate reductase (MTHFR) gene results in a decreased MTHFR activity but to a less extent, it is known as a risk factor of predisposition to human neural tube defects (NTDs), in some populations. Our objective was therefore to study, for the first time in Algerian population, if A1298C polymorphism confers risk for the occurrence of this abnormality. We have examined the distribution of the genotype and the allele frequencies of A1298C mutation, and also their influence on plasma homocysteine (Hcy) concentration. Patients and Methods: We studied this polymorphism in 38 mothers of NTD cases and 67 control individuals of an eastern Algerian population. The mutation was determined by polymerase chain reaction-restriction fragment length polymorphism analysis (PCR/RFLP). Plasma homocysteine concentration was analyzed using an automated chemiluminescence method. Results: No significant association could be observed between allele and genotypes frequencies of A1298C MTHFR gene polymorphism and NTDs risk. However, we could observe that A1298C polymorphism affects homocysteine metabolism in mothers of NTD cases leading to homocysteine concentration values higher in AA genotype and lower in AC/CC genotypes $(15.29 \pm 11.8 \mu \mathrm{mol} / \mathrm{l}$ vs. $8.63 \pm 3.83 \mu \mathrm{mol} / \mathrm{l}, p<0.05)$. Conclusion: Data indicate that $\mathrm{A} 1298 \mathrm{C}$ MTHFR gene polymorphism might be a risk factor by affecting homocysteine metabolism in mothers of Algerian children with NTDs.
\end{abstract}

\section{Keywords}

Methylenetetrahydrofolate Reductase, A1298C Polymorphism, Homocysteine, Neural Tube Defects 


\section{Introduction}

Neural tube defects (NTDs) represent a common group of severe congenital malformations that result from a failure of neural tube closure during early development [1]. Statistics show an incidence of NTDs equal to 7.5 per 1000 births in Algeria [2], very superior to the prevalence observed in other countries [3] [4] [5] [6].

The aetiology of these malformations is complex involving environmental and genetic factors [1] [7]. Abnormalities in folate and homocysteine (Hcy) metabolisms, such as hyperhomocysteinemia or vitamin-cofactor and enzyme deficiencies, may be responsible for these malformations. Methylenetetrahydrofolate reductase is a critical enzyme in these metabolisms. It functions as a methyl donor for the remethylation of homocysteine to methionine, playing a key role in DNA methylation and synthesis involved in the neurulation process [8].

Several mutations have been identified due to the decrease of the methylenetetrahydrofolate reductase (MTHFR) enzyme activity. Most studies focused on the C677T polymorphism (rs1801133), as a risk factor of NTDs [9] [10] [11]. In certain populations, this mutation is associated with an increased risk in infants and their mothers [12] [13] [14] [15].

For its part, A1298C (rs1801131) is a single nucleotide polymorphism representing an $\mathrm{A}$ to $\mathrm{C}$ transversion in exon 7 results in a substitution of glutamic acid residue to an alanine at the position 429 in the regulatory domain of the protein (Van der put et al., 1998). It has been found to be associated with a reduced level of enzyme activity but not as severe as with C677T [16] [17]. Conflicting results exist regarding the association of A1298C MTHFR mutation with NTDs risk [15] [18] [19].

The C677T mutation as a risk factor of neural tube defects in Algerian population has been studied in mothers of NTD infants in our previous work [20]. Obtained results showed that C677T genotype frequencies were not significantly different from those of controls. However, we have shown that this mutation was mainly responsible for the increase of homocysteine among mothers of children having NTDs.

In this study, we have tried to extend our investigation to the A1298C mutation. We examined the genotypes frequencies of the A1298C polymorphism in mothers of NTD infants. We have also investigated the impact of the mutation on homocysteine metabolism.

\section{Material and Methods}

\subsection{Subjects}

The study population included 38 mothers of NTD cases aged between 21 and 41 years, and a control group including 67 mothers aged between 19 and 44 years. They were recruited from the maternity services of the University Hospital of Constantine CHU and from Ouargla Hospital (Constantine and Ouargla are two cities located in the eastern part of Algeria). 
For mothers who had an affected NTD infant we purposely restricted our study to those which are not pregnant at the time of blood sampling and did not use multivitamin supplements or under treatment of any kind. Types of neural tube abnormalities observed in the children of these mothers are essentially, spina bifida and encephalocele.

The control group is composed of women without personal and family history of NTD. They have been selected to fill the same age, socioeconomic level and conditions mentioned above as those of mothers of NTD patients. The local ethics committee approved the protocol and informed consent was obtained from the participant relatives.

\subsection{Metabolite Analysis}

Fasting blood samples were collected in Ethylene Diamine Tetra acetic Acid (EDTA) treated Vacutainer tubes. The plasma obtained by centrifugation at $4000 \mathrm{rpm}$ for 8 min was frozen at $-20^{\circ} \mathrm{C}$ for homocysteine analysis, total plasma homocysteine concentration was determined using the Immulite 2000 system, an automated fluorescence polarization immunoassay based on the reduction of protein-bound homocysteine and mixed disulfide forms. Free homocysteine is enzymatically converted into S-adenosylL-homocysteine, which is then recognized by a monoclonal antibody.

\subsection{Genetic Analyses}

DNA was extracted from blood required in vacutainer K3EDTA tubes using $\mathrm{NaCl}$ method. The principle of the technique is to separate leukocytes of total blood by hypotonic lysis of red blood cells. They are then treated by a detergent sodium dodecyl sulfat (SDS) and proteinase $\mathrm{K}$ to degrade membranes and proteins. Nuclear DNA is released and the proteins associated are eliminated by $\mathrm{NaCl}$ precipitation. The DNA pelot is formed in the supernatant by precipitation with ethanol then solubilized in aqueous phase.

A1298C Polymorphism in MTHFR gene was examined using Polymerase chain reaction-Restriction fragment length polymorphism (PCR-RFLP) analysis.

A 163bp fragment encompassing the 1298 nucleotide of MTHFR gene was amplified using primers as follows: forward 5'CTTTGGGGAGCTGAAGGAC TACTAC3' and reverse 5'-R CACTTTGTGACCATTCCGGTTTG3'. Cycling conditions of PCR were: initial denaturation at $94^{\circ} \mathrm{C}$ for $12 \mathrm{~min}$ followed by 35 cycles of $94^{\circ} \mathrm{C}$ for $30 \mathrm{~s}, 56^{\circ} \mathrm{C}$ for $30 \mathrm{~s}$, and $72^{\circ} \mathrm{C}$ for $30 \mathrm{~s}$ with a final extension for $3 \mathrm{~min}$ at $72^{\circ} \mathrm{C}$. PCR was performed in a total volume of $50 \mu \mathrm{l}$ containing genomic DNA, 25m Mof $\mathrm{MgCl}_{2}, 2.5 \mathrm{~m}$ Mof each deoxynucleotide triphosphate, $40 \mathrm{ng}$ of each primer, $2 \mathrm{U}$ Taq DNA polymerase and $5 \mu \mathrm{l}$ of $10 \mathrm{X}$ reaction buffer. The presence of $\mathrm{C}$ allele abolishes an MboII restriction site. Digestion of the 163-bp fragment of the 1298AA genotype gives five fragments of 56, 31, 30, 28, and 18 $\mathrm{bp}$, whereas the 1298CC genotype results in four fragments, of, namely, 84, 31, 30, and $18 \mathrm{bp}$. Restriction enzyme analysis was used as described previously [16]. 
All fragments were resolved on a 3\% agarose with $1 \%$ nusieve gel.

\subsection{Statistical Analyses}

The risk of NTDs associated with genotype was estimated by odds ratio (OR), with $95 \%$ confidence intervals, the level of significance was set at $\mathrm{P}<0.05$.

The association between A1298C genotypes and the concentration of Hcy was performed using ANOVA test in the case of equal variance and using the Mann Witney test in the case of unequal variance. Statistical analyses were conducted using Epi info software (version 6.0).

\section{Results}

\subsection{Distribution of Genotypic and Allelic Frequencies of the Po- lymorphism A1298C in Mothers of NTD Cases and Control Mothers}

The observed prevalence of gene mutation in control mothers versus mothers of NTD cases are given in Table 1. The polymorphism agree with the Hardy Weinberg equilibrium.

The C allele frequencies of $\mathrm{A} 1298 \mathrm{C}$ polymorphism are of $19.7 \%$ and $15.6 \%$ among mothers of NTD cases, and control mothers, respectively. There is no significant difference between mothers and controls.

Concerning genotypes, the 1298AC genotype frequency is of $34.21 \%$ for mothers against $31.34 \%$ for controls. No increased risk was observed for AC genotype in mothers of NTD cases. The 1298CC genotype is present in only one mother of NTD case $(2.63 \%)$.

\subsection{Effect of Polymorphisms on Homocysteine Levels}

The concentrations of homocysteine stratified by MTHFR genotypes are displayed in Table 2.

The comparison of mean values of homocysteine shows a significant difference between mothers of NTD affected children and control mothers $(p<$ $0.01)$.

Table 1. Genotypic distribution and allelic frequencies of the A1298C mutation of MTHFR gene.

\begin{tabular}{cccccc}
\hline \multirow{2}{*}{ A1298C } & \multicolumn{3}{c}{ Genotypic distribution \%(n) } & \multicolumn{2}{c}{ Allelic frequencies } \\
\cline { 2 - 6 } & \multicolumn{1}{c}{ AA } & AC & CC & A & C \\
\hline Mothers of NTD cases & $63.15(24)$ & $34.21(13)$ & $2.63(1)$ & 0.802 & 0.197 \\
Control Mothers & $68.66(46)$ & $31.34(21)$ & 0 & 0.843 & 0.156 \\
OR mothers x Controls & & & & & $1.32(0.6-2.92)$ \\
CC genotype & ---- & & & \\
AC genotype & \multicolumn{3}{c}{$1.19(0.47-3.02)$} \\
\end{tabular}

OR. Odds Ratio. 
Table 2. Mean homocysteine levels and impact of MTHFR genotypes of A1298C polymorphism on homocysteine concentrations in mothers of NTD cases and in control mothers.

\begin{tabular}{|c|c|c|c|}
\hline & \multicolumn{3}{|c|}{ Mean Homocysteine $(\mu \mathrm{mol} / \mathrm{l})$} \\
\hline Mothers of NTD cases & \multicolumn{3}{|c|}{$14.00 \pm 10.88$} \\
\hline Control mothers & \multicolumn{3}{|c|}{$7.75 \pm 4.58$} \\
\hline$P^{\alpha}$ & \multicolumn{3}{|c|}{$<0.01^{\star *}$} \\
\hline & \multicolumn{3}{|c|}{ MTHA1298C Genotypes } \\
\hline & AA & $\mathrm{AC} / \mathrm{CC}$ & $P^{\wp}$ \\
\hline Mothers of NTD cases (n) & 24 & 14 & \\
\hline Control mothers (n) & 46 & 21 & \\
\hline \multicolumn{4}{|l|}{ Homocysteine $(\mu \mathrm{mol} / \mathrm{l})$} \\
\hline Mothers of NTD cases & $15.29 \pm 11.8$ & $8.63 \pm 3.83$ & $<0.05^{\star}$ \\
\hline Control mothers & $7.82 \pm 3.5$ & $6.7 \pm 4.77$ & NS \\
\hline$P^{+}$ & $=0.01^{\star *}$ & NS & \\
\hline
\end{tabular}

$p^{\mathrm{a}}$ : comparison of mean homocysteine concentration between Mother of NTD cases and Control mothers; $p^{+}$: comparison of homocysteine between Mother of NTD cases and Control mothers regarding genotypes; $p^{\text {s: }}$ comparison of homocysteine between genotypes in Mother of NTD cases and in Control mothers; NS. Not significant.

For the impact of A1298C polymorphism on Hcy concentrations, mothers of NTD cases with 1298AA genotype present significantly higher concentrations of Hcy than those with the $1298 \mathrm{AC} / 1298 \mathrm{CC}$ genotypes $(p<0.05)$. A significant difference was also observed when comparing Hcy levels of AA NTD's mothers and AA control mothers $(p=0.01)$.

The homocysteine concentration was slightly higher in mother controls possessing AA genotype compared with mothers having AC genotype, but the difference was not statistically significant.

\section{Discussion}

Conflicting data have been reported in the literature concerning the association of A1298C mutation and the risk of developing neural tube defects. Difference in the findings could be linked to ethnicity, country of origin or demographic factors. In Algerian population, it is the first work looking to this polymorphism regarding this type of birth defects.

Our results show no significant increase of the mutated allele $\mathrm{C}$ among mothers of NTD cases which is consistent with several previously published studies [21] [22] [23] [24] [25]. No association of the MTHFR 1298C allele and increased risk of NTDs in mothers was observed. In some of these works, lack of association was confirmed in meta-analysis, and also by analysis of case parent-triad data [22] [23]. The only group to find a direct association of the MTHFR 1298C allele is a study carried out by De Marco et al. (2002) [18]. Interaction of 
this polymorphism with other genetic variants, including genes of the folate and the homocysteine metabolic pathways, might be implicated in the pathophysiology of NTDs.

Significant association between mutant genotypes and NTD risk could not be demonstrated. Literature shows studies describing homozygosity and/or heterozygosity of the mutation as a risk factor for these malformations [18], while other works, like in our case, did not report any evidence for a such association among mothers or in children [15] [26] [27] [28] [29]. In the other hand, it was indicated that genetic variants of MTHFR A1298C conferred a protective effect for NTDs in mother groups; the polymorphism significantly decreased the incidence of NTDs [30] [31]. It has been shown that homozygous AA genotype and A allele elevated the risk of NTD development [32].

Regarding the mutation effect on metabolic activity, it has not been reported that mutant AC or CC genotypes cause hyperhomocysteinemia [16].

In the current study, investigation of A1298C polymorphism as a NTD risk appears to be negative, but association of this polymorphism with the increase of Hcy level strengthen its contribution in NTDs occurrence. With NTD's mother of our population, A1298C polymorphism affects homocysteine metabolism showing a higher Hcy in AA genotype and a lower values in mutant AC/CC genotypes. The significant difference in Hcy values observed between mothers of NTD cases and control mothers with AA Genotype confirms our finding, that is, the elevation of the mean Hcy level found in NTDs mothers can be linked, even partly, with this genotype.

Our observations support indeed works highlighted above [30] [31] [32]. In addition, always in agreement with our data, works carried out on NTD infants, showed that NTDs children with normal 1298AA genotype had an increased total homocysteine compared to those with 1298AC/CC mutant genotypes. Children with the genotype 1298AA even presented a low level of erythrocyte folate and vitamin B12 [21].

More recently, in the frame of a large study [33], an increase of Hcy in the wild-type and lower values in mutated homozygous individuals could be observed. Serum folate exhibited an opposite profile; its rate is higher in individuals with mutant genotype CC compared to subjects with normal genotype AA.

These interesting results should be considered in future investigations to better understand the A1298C polymorphism effect. It is now clear that it contribute in an alteration of one-carbon metabolism in NTD's mother, but the mechanism of this disturbance remains ambiguous. The polymorphism does not show the same effect on homocysteine rate in control mothers. This can be explained by the multifactorial origin of NTDs. Some specific genetics in mothers of affected children may contribute to the disturbance of Hcy metabolism.

\section{Conclusion}

Our data indicate that A1298C MTHFR gene polymorphism affects homocyste- 
ine metabolism in mothers of Algerian children with NTDs. More studies are required to understand the potential impact of this polymorphism on homocysteine level and folate metabolism. The present work is planned to be continued over coming years, after expanding the sample size, in order to confirm and better understand the preliminary results.

\section{Acknowledgements}

The authors are very grateful to Professor Pascale Hilbert from the Institute of Pathology and Genetics IPG (Gosselies, Belgium) for her kindly help to achieve the study as well as her team for their technical assistance.

\section{Conflicts of Interest}

The authors declare no conflicts of int regarding the publication of this paper.

\section{References}

[1] Salder, T.W and Langman, J. (2018) Embryologie Médicale. $9^{\text {ème }}$ Edition, Pradel, États-Unis.

[2] Houcher, B., Bourouba, R., Djabi, F. and Houcher, Z. (2008) The Prevalence of Neural Tube Defects in Setif University Maternity Hospital, Algeria-3 Years Review (2004-2006). Pteridines, 19, 12-18. https://doi.org/10.1515/pteridines.2008.19.1.12

[3] De Wals, P., Tairou, F., VanAllen, M., Uh, S.H., Lowry, R.B., Sibbald, B., Evans, J.A., Van denHof, M.C., Zimmer, P., Crowley, M., Fernandez, B., Lee, N.S. and Niyonsenga, T. (2007) Reduction in Neural Tube Defects after Folic Acid Fortification in Canada. New England Journal of Medicine, 357, 135-142. https://doi.org/10.1056/NEJMoa067103

[4] Golalipour, M.J., Mobasheri, E., Vakili, M.A. and Keshtkar, A.A. (2007) Epidemiology of Neural Tube Defects in Northern Iran, 1998-2003. Eastern Mediterranean Health Journal, 3, 560-566.

[5] Bhid, P., Sagoo, G.S., Moorty, S., Burton, H. and Kar, A. (2013) Systematic Review of Birth Prevalence of Neural Tube Defects in India. Birth Defects Research Part A Clinical and Molecular Teratology, 97, 437-443. https://doi.org/10.1002/bdra.23153

[6] Khoshnood, B., Loane, M., de Walle, H., Arriola, L., Addor, M., Barisic, I., Beres, J., Bianchi, F., Dias, C., Draper, E., Garne, E., Gatt, M., Haeusler, M., Klungsoyr, K., Latos-Bielenska, A., Lynch, C., McDonnell, B., Nelen, V., Neville, A.J., O’Mahony, M.T., Queisser-Luft, A., Rankin, J., Rissmann, A., Ritvanen, A., Rounding, C., Sipek, A., Tucker, D., Verellen-Dumoulin, C., Wellesley, D. and Dolk, H. (2015) Long Term Trends in Prevalence of Neural Tube Defects in Europe: Population Based Study. British Medical Journal, 351, h5949. https://doi.org/10.1136/bmj.h5949

[7] Frey, L. and Hauser, W.A. (2003) Epidemiology of Neural Tube Defects. Epilepsia, 44, 4-13. https://doi.org/10.1046/j.1528-1157.44.s3.2.x

[8] Ueland, P.M. and Rozen, R. (2005) MTHFR Polymorphisms and Disease. Landes Bioscience, Georgetown. https://doi.org/10.1201/9781498713887

[9] Yan, L., Zhao, L., Long, Y., Zou, P., Ji, G., Gu, A. and Zhao, P. (2012) Association of the Maternal MTHFR C677T Polymorphism with Susceptibility to Neural Tube Defects in Offsprings: Evidence from 25 Case-Control Studies. PLoS ONE, 7, e41689. https://doi.org/10.1371/journal.pone.0041689 
[10] Yu, Y., Wang, F., Bao, Y., Lu, X., Quan, L. and Lu, P. (2014) Association between MTHFR Gene Polymorphism and NTDs in Chinese Han Population. International Journal of Clinical and Experimental Medicine, 7, 2901-2906.

[11] Yang, Y., Chen, J., Wang, B., Ding, C. and Liu, H. (2015) Association between MTHFR C677T Polymorphism and Neural Tube Defect Risks: A Comprehensive Evaluation in Three Groups of NTD Patients, Mothers, and Fathers. Birth Defects Research Part A Clinical and Molecular Teratology, 103, 488-500.

https://doi.org/10.1002/bdra.23361

[12] Van der Put, N.M.J., Steegers-Theunissen, R.P.M., Frosst, P., Trijbels, F.J.M., Eskes, T.K.A.B., van den Heuvel, L.P., Mariman, E.C., den Heyer, M., Rozen, R. and Blom, H.J. (1995) Mutated Methylenetetrahydrofolate Reductase as a Risk Factor for Spina Bifida. The Lancet, 346, 1070-1071. https://doi.org/10.1016/S0140-6736(95)91743-8

[13] Shields, D.C., Kirke, P.N., Mills, J.L., Ramsbottom, D., Molloy, A.M., Burke, H., Weir, D.G., Scott, J.M. and Whitehead, A.S. (1999) The "Thermolabile" Variant of Methylenetetrahydrofolate Reductase and Neural Tube Defects: An Evaluation of Genetic Risk and the Relative Importance of the Genotypes of the Embryo and the Mother. American Journal of Human Genetics, 64, 1045-1055.

https://doi.org/10.1086/302310

[14] Johanning, G.L., Tamura, T., Johnston, K.E. and Wenstrom, K. (2000) Comorbidity of 5,10-Methylenetetrahydrofolate Reductase and Methionine Synthase Gene Polymorphisms and Risk for Neural Tube Defects. Journal of Medical Genetics, 37, 949-951. https://doi.org/10.1136/jmg.37.12.949

[15] Liu, J., Qi, J., Yu, X., Zhu, J., Zhang, L., Ning, Q. and Luo, X. (2014) Investigations of Single Nucleotide Polymorphisms in Folate Pathway Genes in Chinese Families with Neural Tube Defects. Journal of the Neurological Sciences, 337, 61-66. https://doi.org/10.1016/j.jns.2013.11.017

[16] Van der Put, N.M.J., Gabreels, F., Stevens, E.M., Smeitink, J.A., Trijbels, F.J., Eskes, T.K., Van den Heuvel, L.P. and Blom, H.J. (1998) A Second Common Mutation in the Methylene-Tetrahydrofolatereductase Gene: An Additional Risk for Neural-Tube Defects? American Journal of Human Genetics, 62, 1044-1051. https://doi.org/10.1086/301825

[17] Weisberg, I., Tran, P., Christensen, B., Sibani, S. and Rozen, R. (1998) A Second Genetic Polymorphism in Methylenetetrahydrofolate Reductase (MTHFR) Associated with Decreased Enzyme Activity. Molecular Genetics and Metabolism, 64, 169-172. https://doi.org/10.1006/mgme.1998.2714

[18] De Marco, P., Calevo, M.G., Moroni, A., Arata, L., Merello, E., Finnell, R.H., Zhu H., Andreasi, L., Cama, A. and Capra, V. (2002) Study of MTHFR and MS Polymorphisms as Risk Factors for NTD in the Italian Population. Journal of Human Genetics, 47, 319-324. https://doi.org/10.1007/s100380200043

[19] Boduroğlu, K. (2005) Analysis of MTHFR 1298A > C in Addition to MTHFR 677C > T Polymorphism as a Risk Factor for Neural Tube Defects in the Turkish Population. Turkish Journal of Pediatrics, 47, 327-333.

[20] Abbas, A., Abadi, N., Naimi, D., Sifi, K. and Benlatreche, C. (2012) Mutation C677T Research in Gene Coding for Methylene Tetrahydrofolate Reductase (MTHFR) in Neural Tube Defects (NTDs) in Constantine. Immuno-analyse et biologie spécialisée, 27, 122-127. https://doi.org/10.1016/j.immbio.2012.02.004

[21] Cunha, A.L., Hirata, M.H., Kim, C.A., Guerra-Shinohara, E.M., Nonoyama, K. and Hirata, R.D. (2002) Metabolic Effects of C677T and A1298C Mutations at the MTHFR Gene in Brazilian Children with Neural Tube Defects. Clinica Chimica Acta, 318, 139-143. https://doi.org/10.1016/S0009-8981(01)00764-1 
[22] Parle-McDermott, A., Mills, J.L., Kirke, P.N., O’Leary, V.B., Swanson, D.A., Pangilinan, F., Conley, M., Conley, M., Molloy, A.M., Cox, C., Scott, J.M. and Brody, L.C. (2003) Analysis of the MTHFR 1298AC and 677T Polymorphisms as Risk Factors for Neural Tube Defects. Journal of Human Genetics, 48, 190-193. https://doi.org/10.1007/s10038-003-0008-4

[23] Zhang, Y., He, X., Xiong, X., Chuan, J., Zhong, L., Chen, G. and Yu, D. (2019) The Association between Maternal Methylenetetrahydrofolate Reductase C677T and A1298C Polymorphism and Birth Defects and Adverse Pregnancy Outcomes. Prenatal Diagnosis, 39, 3-9. https://doi.org/10.1002/pd.5396

[24] Felix, T.M., Leistner, S. and Giugliani, R. (2004) Metabolic Effects and the Methylenetetrahydrofolate Reductase (MTHFR) Polymorphism Associated with Neural Tube Defects in Southern Brazil. Birth Defects Research Part A Clinical and Molecular Teratology, 70, 459-463. https://doi.org/10.1002/bdra.20011

[25] Sadewa, A.H., Sutomo, R., Istiadjid, M., Nishiyama, K., Shirakawa, T., Matsuo, M. and Nishio, H. (2004) C677T Mutation in the MTHFR Gene Was Not Found in Patients with Fronto Ethmoidal Encephalocele in East Java, Indonesia. Pediatrics International, 46, 409-414. https://doi.org/10.1111/j.1442-200x.2004.01927.x

[26] Relton, C.L., Wilding, C.S., Laffling, A.J., Jonas, P.A., Burgess, T., Binks, K., Tawn, E.J. and Burn, J. (2004) Low Erythrocyte Folate Status and Polymorphic Variation in Folate-Related Genes Are Associated with Risk of Neural Tube Defect Pregnancy. Molecular Genetics and Metabolism, 81, 273-281. https://doi.org/10.1016/j.ymgme.2003.12.010

[27] Behunova, J., Klimcakova, L., Zavadilikova, E., Podracka, L. and Potocekova, D. (2010) Methylenetetrahydrofolate Reductase Gene Polymorphisms and Neural Tube Defects Epidemiology in the Slovak Population. Birth Defects Research Part A Clinical and Molecular Teratology, 88, 695-700. https://doi.org/10.1002/bdra.20692

[28] Soleimani-Jadidi, S., Meibodi, B., Javaheri, A., Tabatabaei, R.S., Hadadan, A., Zanbagh L., Abbasi, H., Bahrami, R., Mirjalili, S.R., Karimi-Zarchi, M. and Neamatzadeh, H. (2020) Association between Fetal MTHFR A1298C (rs1801131) Polymorphism and Neural Tube Defects Risk: A Systematic Review and Meta-Analysis. Fetal and Pediatric Pathology. https://doi.org/10.1080/15513815.2020.1764682

[29] Aranda-Sánchez, C.I., Bobadilla-Morales, L., Corona-Rivera, A., Cuero-Quezada, I., Santana-Hernández, J., Baldomero-López, A., Romero-Bolaño, Y.M., Peña-Padilla, C. and Corona-Rivera, J.R. (2021) MTHFR C677T and A1298C Variants in Mexican Mestizo Infants with Neural Tube Defects from Western Mexico. Congenital Anomalies. (Online Ahead of Print)

[30] Wang, X., Liu, Y., Ji, W., Qin, H., Wu, H., Xu, D., Turtuohut, T. and Wang, Z. (2015) Variants in MTHFR Gene and Neural Tube Defects Susceptibility in China. Metabolic Brain Disease, 30, 1017-1026. https://doi.org/10.1007/s11011-015-9662-4

[31] Nasri, K., Midani, F., Kallel, A., Ben Jemaa, N., Aloui, M., Boulares, M., Lassoued, M., Ben Halima, M., Ben Wafi, S., Soussi, M., Mahjoubi, I., Baara, A., Ben Fradj, M.K., Omar, S., Feki, M., Jemaa, R., Gaigi, S.S. and Marrakchi, R. (2019) Association of MTHFR C677T, MTHFR A1298C, and MTRR A66G Polymorphisms with Neural Tube Defects in Tunisian Parents. Pathobiology, 86, 190-200.

https://doi.org/10.1159/000499498

[32] Kamasak, K., Yegin, Z. and Yildirim, I.H. (2020) Analysis of Factor V and MTHFR Genes as Risk Factors Constituting Susceptibility to Neural Tube Defects: A CaseControl Study from Turkey. Kirıkkale Üniversitesi Tıp Fakültesi Dergisi, 22, 105-112. https://doi.org/10.24938/kutfd.676442 
[33] Zappacosta, B., Graziano, M., Persichilli, S., Di Castelnuovo, A., Mastroiacovo, P. and Iacoviello, L. (2014) 5,10-Methylenetetrahydrofolate Reductase (MTHFR) C677T and A1298C Polymorphisms: Genotype Frequency and Association with Homocysteine and Folate Levels in Middle-Southern Italian Adults. Cell Biochemistry and Function, 32, 1-4. https://doi.org/10.1002/cbf.3019 